\title{
The effects of transport mode use on self-perceived health, mental health, and social contact measures: A cross-sectional and longitudinal study
}

\author{
Ione Avila-Palencia ${ }^{\mathrm{a}, \mathrm{b}, \mathrm{c}}$, Luc Int Panis ${ }^{\mathrm{d}, \mathrm{e}}$, Evi Dons ${ }^{\mathrm{d}, \mathrm{f}}$, Mailin Gaupp-Berghausen ${ }^{\mathrm{g}}$, Elisabeth Raser ${ }^{\mathrm{g}}$, \\ Thomas Götschi ${ }^{\mathrm{h}}$, Regine Gerike ${ }^{\mathrm{i}}$, Christian Brand ${ }^{\mathrm{j}}$, Audrey de Nazelle ${ }^{\mathrm{k}}$, Juan Pablo Orjuela ${ }^{\mathrm{k}}$, \\ Esther Anaya-Boig ${ }^{\mathrm{k}}$, Erik Stigell ${ }^{\mathrm{l}}$, Sonja Kahlmeier ${ }^{\mathrm{h}}$, Francesco Iacorossi ${ }^{\mathrm{m}}$, \\ Mark J. Nieuwenhuijsen ${ }^{\text {a,b,c,* }}$
}

a ISGlobal, Barcelona Institute for Global Health - Campus Mar, Barcelona Biomedical Research Park (PRBB), Doctor Aiguader, 88, 08003 Barcelona, Spain
b Universitat Pompeu Fabra (UPF) - Campus Mar, Barcelona Biomedical Research Park (PRBB), Doctor Aiguader, 88, 08003 Barcelona, Spain
${ }^{\mathrm{c}}$ CIBER Epidemiología y Salud Pública (CIBERESP), Av. Monforte de Lemos, 3-5, Pabellón 11, Planta 0, 28029 Madrid, Spain
${ }^{\mathrm{d}}$ Flemish Institute for Technological Research (VITO), Boeretang 200, 2400 Mol, Belgium
$\mathrm{e}^{\mathrm{e}}$ Transportation Research Institute (IMOB), Hasselt University, Wetenschapspark 5/6, 3590 Diepenbeek, Belgium
${ }^{\mathrm{f}}$ Centre for Environmental Sciences (CMK), Hasselt University, Martelarenlaan 42, 3500 Hasselt, Belgium
${ }^{\mathrm{g}}$ Institute for Transport Studies, University of Natural Resources and Life Sciences, Peter-Jordan-Straße 82, 1190 Vienna, Austria
${ }^{\mathrm{h}}$ Epidemiology, Biostatistics and Prevention Institute, University of Zurich, Hirschengraben 84, 8001 Zürich, Switzerland
${ }^{\mathrm{i}}$ Dresden University of Technology, Chair of Integrated Transport Planning and Traffic Engineering, Hettnerstraße 1, 01062 Dresden, Germany
${ }^{\mathrm{j}}$ Transport Studies Unit, University of Oxford, South Parks Road, Oxford OX1 3QY, United Kingdom
${ }^{\mathrm{k}}$ Centre for Environmental Policy (CEP), Imperial College London, 16-18 Prince's Gardens, London SW7 1NE, United Kingdom
${ }^{1}$ Trivector Traffic, Barnhusgatan 16, SE-111 23 Stockholm, Sweden
${ }^{\mathrm{m}}$ Roma Servizi per la Mobilità, Via di Vigna Murata 60, O0143 Roma, Italy

\section{A R T I C L E I N F O}

\section{Keywords:}

Bicycling

Walking

Mental health

Loneliness

Questionnaires

Cities

\begin{abstract}
A B S T R A C T
Background: Transport mode choice has been associated with different health risks and benefits depending on which transport mode is used. We aimed to evaluate the association between different transport modes use and several health and social contact measures.

Methods: We based our analyses on the Physical Activity through Sustainable Transport Approaches (PASTA) longitudinal study, conducted over a period of two years in seven European cities. 8802 participants finished the baseline questionnaire, and 3567 answered the final questionnaire. Participants were 18 years of age or older (16 years of age or older in Zurich) and lived, worked and/or studied in one of the case-study cities. Associations between transport mode use and health/social contact measures were estimated using mixed-effects logistic regression models, linear regression models, and logistic regression models according to the data available. All the associations were assessed with single and multiple transport mode models. All models were adjusted for potential confounders.

Results: In multiple transport mode models, bicycle use was associated with good self-perceived health [OR (CI $95 \%)=1.07(1.05,1.08)]$, all the mental health measures [perceived stress: coef $(\mathrm{CI} 95 \%)=-0.016(-0.028$, $-0.004)$; mental health: coef $(\mathrm{CI} 95 \%)=0.11(0.05,0.18)$; vitality: coef $(\mathrm{CI} 95 \%)=0.14(0.07,0.22)]$, and with fewer feelings of loneliness [coef $(\mathrm{CI} 95 \%)=-0.03(-0.05,-0.01)]$. Walking was associated with good self-perceived health [OR $(\mathrm{CI} 95 \%)=1.02(1.00,1.03)]$, higher vitality [coef (CI 95\%) $=0.14(0.05,0.23)$ ], and more frequent contact with friends/family $[\mathrm{OR}(\mathrm{CI} 95 \%)=1.03(1.00,1.05)]$. Car use was associated with fewer feelings of loneliness [coef $(\mathrm{CI} 95 \%)=-0.04(-0.06,-0.02)]$. The results for e-bike and public transport use were non-significant, and the results for motorbike use were inconclusive.

Conclusions: Similarity of findings across cities suggested that active transport, especially bicycle use, should be encouraged to improve population health and social outcomes.
\end{abstract}

\footnotetext{
* Corresponding author at: ISGlobal, Doctor Aiguader, 88, 08003 Barcelona, Spain.

E-mail address: mark.nieuwenhuijsen@isglobal.org (M.J. Nieuwenhuijsen).
} 


\section{Introduction}

To design cities able to produce health and well-being outcomes, it has being suggested that transport planning should assume a major role (Giles-Corti et al., 2016). Transport is associated with economic and social development, but also with different health risks and benefits depending on which transport mode is used (Nieuwenhuijsen et al., 2016). Car use in cities has been associated with negative effects, including congestion, use of physical space, noise, heat, emissions of greenhouse gases, air pollution exposure and lack of physical activity (Dons et al., 2013; Nieuwenhuijsen and Khreis, 2016). Driving time has been associated with high stress (Novaco and Gonzalez, 2009; Legrain et al., 2015; Mattisson et al., 2016), lower psychological well-being (Martin et al., 2014) and more recently also with cognitive decline (Bakrania et al., 2017). Motorbike use has been associated with particularly high risks for injuries, disability, and deaths due to traffic crashes (Rodrigues et al., 2014). Public transport use has often been associated with low travel satisfaction (Novaco and Gonzalez, 2009), but also with psychological well-being (Martin et al., 2014), and increased physical activity levels and reduced BMI (Rissel et al., 2012; Sener et al., 2016; Brown et al., 2015). Active transport - i.e. walking and bicycling - has been associated with multiple health benefits including lower all-cause mortality (Kelly et al., 2014; Celis-Morales et al., 2017), cardiovascular risk (Celis-Morales et al., 2017; Hamer and Chida, 2008; Xu et al., 2013; Oja et al., 2011), body weight (Xu et al., 2013; Wanner et al., 2012), diabetes risk (Saunders et al., 2013), risk of being stressed (Avila-Palencia et al., 2017), better physical and mental well-being (Martin et al., 2014; Humphreys et al., 2013), and health-related quality of life (de Geus et al., 2008). Active transport has also been shown to have other societal benefits such as helping reduce air pollution, greenhouse gas emissions, and noise, and improving social interaction (de Nazelle et al., 2011; Brand et al., 2013).

Until now studies have assessed associations between a single transport mode and health outcomes or made comparisons across transport modes when evaluating associations with health outcomes. We are not aware of any studies that have assessed how the use of multiple transport modes (multi-modality) is related to health, which may be a more realistic description of transport behaviour for many people nowadays. Further, few studies have evaluated associations between transport and social capital indicators showing its relevance (Besser et al., 2008; Mattisson et al., 2015), but none have evaluated associations between transport and loneliness, although loneliness is currently considered to be a major problem in Western society (de Gierveld et al., 2016). Moreover, most studies in transport and health are cross-sectional and conducted in one country. Consequently, international and longitudinal studies are needed to represent variability in transport behaviour.

The main aim of this study was to evaluate the association between different transport modes use and several health and social contact measures in an adult population in seven European cities.

\section{Materials and methods}

\subsection{Study design and population}

A longitudinal study was performed in seven European cities (Antwerp, Barcelona, London, Örebro, Rome, Vienna, and Zurich) as part of the PASTA project (Gerike et al., 2016). Participants were recruited opportunistically on a rolling basis between November 2014 and November 2016. Participants were 18 years of age or older (16 years of age or older in Zurich) and lived, worked and/or studied in one of the case-study cities (Gaupp-Berghausen et al., n.d.). Participants responded to two comprehensive questionnaires (baseline and final) asking for their socio-demographics, travel behaviour, and different health measures, using an on-line survey platform (details of measures obtained from each questionnaire in Supplementary material Fig. S1).
The baseline questionnaire was active between November 2014 and January 2017, and in November 2016 all registered participants were invited to complete the final questionnaire. Between the two questionnaires there was not any specific intervention designed by the study, the participants were doing their normal life. The questions were developed first in English and then translated into Dutch, Spanish, Catalan, Swedish, Italian, and German. The study protocol was approved by the ethics committees from the different case-study cities and written informed consent was obtained from all participants.

\subsection{Transport mode use}

The PASTA longitudinal study assessed transport mode use in the baseline and final questionnaires by asking: "How often do you currently use each of the following methods of travel to get to and from places?" with possible transport modes being: car or van/public transport/motorcycle or moped/electric bicycle/bicycle/walk. Answers for each transport mode were rated on a five-point scale ranging from "Daily or almost daily" to "Never". Each transport mode was converted to a continuous variable assigning a value (frequency) to each of the categories of the scale: "Daily or almost daily" $=24$ days per month; "on 1-3 days per week" $=8$ days per month; "on 1-3 days per month" = 2 days per month; "Less than once per month" $=1$ day per month; "Never" $=0$ days per month. We created an additional variable for each transport mode calculating the mean between the two questionnaires as a proxy of long-term use.

As part of the sensitivity analyses, we created dichotomous variables for each transport mode use. First, we created two categories using the original scale: "at least once per week" (Daily or almost daily/on 1-3 days per week) and "less than once per week" (on 1-3 days per month/Less than once per month/Never). Second, we dichotomized the mean variables using the value 5 as a cut-off and used the same categories as the previous one ("at least once per week" and "less than once per week"). We considered "less than once per week" answers as the reference category.

\subsection{Health and social contact measures}

Our main outcome was self-perceived health. We used the scale from The Medical Outcome Study Short Form (SF-36) asking participants: "In general, how would you say your health is?" with possible responses being: excellent/very good/good/fair/poor. The answers were dichotomized by whether people had a "good self-perceived health" (excellent/very good/good) or "poor self-perceived health" (fair/poor), following the same methodology used in previous studies (Dadvand et al., 2016). We considered "poor self-perceived health" answers as the reference category, therefore a positive association between transport mode use and this variable could be interpreted as good self-perceived health. Self-perceived health was measured in the baseline and in the final questionnaires.

We used three mental health measures: perceived stress, mental health, and vitality. First, perceived stress was measured using the short version of the Perceived Stress Scale (PSS-4) (Cohen et al., 1983). The instrument contains four statements, which measure how unpredictable, uncontrollable, and overloaded respondents feel that their lives are. The higher the score on the PSS-4 (from 0 to 16), the greater the respondent perceives that their demands exceed their ability to cope. Second, to measure mental health we used the 5-item mental health scale of SF-36 (MHI-5). It includes items from each of the four major mental health dimensions (anxiety, depression, loss of behavioural/emotional control, and psychological well-being). The lowest value possible (floor) would be "feelings of nervousness and depression all of the time" and the highest possible (ceiling) would be for someone who "feels peaceful, happy, and calm all of the time" (Ware et al., 1993). Third, we used a four-item measure of vitality (energy level and fatigue) from SF-36 which captures differences in subjective well-being. 
The lowest value possible (floor) would be someone who "feels tired and worn out all of the time" and the highest value possible (ceiling) would be someone who "feels full of pep/life and energy all of the time" (Ware et al., 1993). On mental health and vitality scales, all items were scored on a 6-point scale and summed scores were transformed into a scale from 0 to 100 , following SF-36 scoring guidelines. Perceived stress, mental health, and vitality were measured only in the final questionnaire.

We used two social contact measures: loneliness and contact with friends and/or family. Feelings of loneliness are understood as the result of a deficient (quantitatively or qualitatively) social network, and the objective characteristics of a social network can go from social isolation to social participation (de Gierveld et al., 2016). Loneliness was assessed with six statements based on the UCLA loneliness scale (e.g. feelings of isolation, feeling as part of a group of friends) (Russel, 1996). Participants were asked to indicate to what extent they agreed with the statements on a 5-point scale ranging from "totally agree" (1) to "totally disagree" (5). A sum score was calculated (from 6 to 30) with higher scores indicating greater feelings of loneliness. With regards to contact with friends and/or family, participants were asked "How often do you have contact with your friends and/or family?" with possible responses being: (almost) Daily/At least once a week/1-3 times per month/less than once a month/seldom or never. The answers were dichotomized on whether people contacted friends and/or family "At least once a week" ((almost) Daily/At least once a week) or "less than once a week" (1-3 times per month/less than once a month/seldom or never). We considered "less than once a week" answers as the reference category, therefore a positive association between transport mode use and this variable could be interpreted as frequent contact with friends and/or family. Loneliness and contact with friends and/or family were measured only in the final questionnaire.

\subsection{Other explanatory measures}

Date of birth, sex, educational level, nationality, employment status, physical activity (working, recreational, transport, overall) and sedentary (sitting) behaviours were obtained only in the baseline questionnaire. Weight and height were obtained in the baseline and in the final questionnaires. Any change in employment status, and life events like moving home or starting a new job were obtained in the final questionnaire. Age was calculated for the baseline and final questionnaire taking into account the date when the participants answered each questionnaire and their date of birth. Educational level, nationality, and employment status were used as proxies of Socio-Economical Status (SES). They were dichotomized in "university or higher education", "local nationality" (as having the nationality from the country where the participant lived while answering the questionnaires), "fulltime employed" respectively. The physical activity (working, recreational, transport, overall) and sedentary (sitting) behaviours were assumed constant in both time points. Through the available individual characteristics, relevant confounders were defined a priori based on a Direct Acyclic Graph (DAG) (Supplementary material Fig. S2).

\subsection{Statistical analyses}

Descriptive univariate analyses were conducted for all study variables, calculating frequencies and percentages for categorical variables; and mean, standard deviation (SD), median, and interquartile range (IQR) for continuous variables to characterize the study population. Descriptive bivariate analyses were conducted using Kruskal Wallis tests to assess travel behaviour through the seven case-study cities, and Chi square and U Mann Whitney tests to assess the statistical differences between baseline and final questionnaire populations.

Regression models were run to assess associations between transport mode use and all the health and social contact measures. First, mixed-effects logistic regression models were used to evaluate the association between transport mode use and self-perceived health. Transport mode measures from baseline and final questionnaires were used as exposure variables and participant was used as a random effect for repeated measures. This repeated measures design was unbalanced, as it included all the participants at baseline and not only those with two measurements. Second, linear regression models were used to evaluate the association between transport mode use and perceived stress, mental health, vitality, and loneliness; and logistic regression models were used to evaluate the association between transport mode use and contact with friends and/or family. No repeated measures design was used for any of these outcomes as these were measured only once (in the final questionnaire). The mean of each transport mode between baseline and final questionnaires was used as exposure variable.

The different associations were assessed using two transport mode models approach: (1) single transport mode models and (2) multiple transport mode models. In the single transport mode models only one transport mode was used at a time as exposure, and in the multiple transport mode models all different transport modes were included in the model to be able to assess multiple transport mode behaviours. This multiple transport mode approach is not a definition of multi-mode transport for trips, but overall participants who used multiple transport modes in general. Polychoric analyses were conducted to assess the correlation between the different transport modes (Supplementary material Table S1). All regression models were run: (0) unadjusted, (1) adjusted for age and sex, and (2) adjusted for the confounders identified by the DAG. All models used city as a fixed effect and were conducted with a complete case analysis. In all contrasts a significance value of $\mathrm{p}<0.05$ was considered. All models were conducted first with pooled analyses with all cities together and second stratified by city using fixed effects meta-analyses as sensitivity analyses. The meta-analyses were conducted to compare the effects of transport mode use on the outcomes between cities, as the frequency of transport mode use was different across cities (Table 1). All models were run with transport mode use as continuous variables (main analyses) and as dichotomous variables (sensitivity analyses). All analyses were conducted in Stata version SE 14 (StataCorp LP, Texas USA).

\section{Results}

Out of the 10,719 participants with clean data, 8828 answered the self-perceived health question in the baseline and/or final questionnaire. Of these, 8802 finished the baseline questionnaire, and a subsample of 3567 also answered the final questionnaire. The sociodemographic characteristics of study population, prevalence of health and social contact measures, and description of transport mode use distribution are presented in Table 2.

Table 3 shows the associations between the different transport mode uses and the health and social contact measures, adjusted for all the relevant confounders. In the single mode models, a higher frequency of driving a car was statistically significantly associated with lower odds of having good self-perceived health, lower levels of vitality, and fewer feelings of loneliness. Those who used public transport more frequently had statistically significant lower odds of having good self-perceived health. Those who rode a bicycle more frequently had statistically significant higher odds of having good self-perceived health, less perceived stress, better mental health, and higher vitality. A higher frequency of walking was statistically significantly associated with higher levels of vitality.

In the multiple mode models the results were marginally different. A higher frequency of driving a car and riding a motorbike were statistically significantly associated with fewer feelings of loneliness. Bicycle use was statistically significantly associated with higher odds of having good self-perceived health, lower perceived stress, better mental health, and higher vitality, and was statistically significantly associated with fewer feelings of loneliness. Walking was statistically significantly 
Table 1

Distribution of transport mode use in the different case-study cities according to each questionnaire.

\begin{tabular}{|c|c|c|c|c|c|c|c|c|}
\hline & $\begin{array}{l}\text { Antwerp } \\
(\mathrm{n}=1294)\end{array}$ & $\begin{array}{l}\text { Barcelona } \\
(\mathrm{n}=1399)\end{array}$ & $\begin{array}{l}\text { London } \\
(\mathrm{n}=1089)\end{array}$ & $\begin{array}{l}\text { Oerebro } \\
(\mathrm{n}=1067)\end{array}$ & $\begin{array}{l}\text { Rome } \\
(n=1585)\end{array}$ & $\begin{array}{l}\text { Vienna } \\
(\mathrm{n}=1204)\end{array}$ & $\begin{array}{l}\text { Zurich } \\
(\mathrm{n}=1164)\end{array}$ & p-Value ${ }^{a}$ \\
\hline \multicolumn{9}{|c|}{ Baseline questionnaire $(\mathrm{n}=8802)$} \\
\hline \multicolumn{9}{|c|}{ Transport mode (days/month) } \\
\hline Car & $7.96(7.37)$ & $4.63(6.56)$ & $4.77(6.93)$ & $10.01(8.91)$ & $9.21(9.04)$ & $4.68(6.66)$ & $4.60(6.45)$ & 0.0001 \\
\hline Motorbike & $0.15(1.22)$ & $2.44(6.69)$ & $0.20(1.78)$ & $0.26(1.94)$ & $3.47(7.67)$ & $0.40(2.41)$ & $0.89(3.95)$ & 0.0001 \\
\hline Public transport & $5.29(7.64)$ & $14.23(9.62)$ & $13.49(9.46)$ & $3.42(6.16)$ & $12.65(10.43)$ & $16.14(9.54)$ & $16.25(9.53)$ & 0.0001 \\
\hline E-bike & $1.53(5.4)$ & $0.15(1.64)$ & $0.04(0.50)$ & $0.22(2.03)$ & $0.69(3.79)$ & $0.30(2.21)$ & $1.09(4.51)$ & 0.0001 \\
\hline Bicycle & $18.93(8.57)$ & $8.00(10.07)$ & $8.58(10.55)$ & $14.28(10.31)$ & $7.32(9.63)$ & $9.72(10.30)$ & $10.07(10.40)$ & 0.0001 \\
\hline Walking & $14.83(9.58)$ & $21.18(6.66)$ & $20.61(7.20)$ & $17.70(8.98)$ & $18.14(9.13)$ & $21.68(6.12)$ & $21.02(6.85)$ & 0.0001 \\
\hline \multicolumn{9}{|c|}{ Final questionnaire $(n=3567)$} \\
\hline \multicolumn{9}{|c|}{ Transport mode (days/month) } \\
\hline Car & $8.04(7.07)$ & $5.08(6.53)$ & $4.93(6.58)$ & $10.11(8.63)$ & $9.43(8.78)$ & $5.19(6.82)$ & $5.10(6.72)$ & 0.0001 \\
\hline Motorbike & $0.28(2.30)$ & $1.87(5.56)$ & $0.25(2.02)$ & $0.29(2.31)$ & $3.41(7.55)$ & $0.38(2.27)$ & $0.74(3.50)$ & 0.0001 \\
\hline Public transport & $4.66(6.94)$ & $13.74(9.45)$ & 11.94 (9.13) & $3.16(5.94)$ & $12.32(10.30)$ & 15.14 (9.59) & 15.39 (9.47) & 0.0001 \\
\hline E-bike & 2.34 (6.59) & $0.33(2.26)$ & $0.19(1.71)$ & $0.51(3.04)$ & $1.06(4.60)$ & $0.54(3.11)$ & $1.63(5.33)$ & 0.0001 \\
\hline Bicycle & $18.23(9.06)$ & 7.61 (9.95) & 9.24 (10.58) & $12.38(10.46)$ & 7.44 (9.58) & 8.60 (9.99) & 9.04 (10.14) & 0.0001 \\
\hline Walking & $12.08(9.24)$ & $20.89(6.75)$ & 19.51 (7.69) & $14.46(9.43)$ & $18.40(8.61)$ & $19.54(7.57)$ & $19.30(7.93)$ & 0.0001 \\
\hline
\end{tabular}

${ }^{\text {a }}$ Kruskal Wallis test. Values shown as mean (SD). Missing data in the Baseline Questionnaire: Car (51; 0.58\%); Motorbike (65; 0.74\%); Public transport (33;

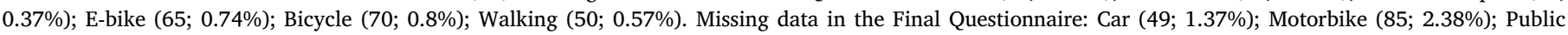
transport (44; 1.23\%); E-bike (88; 2.47\%); Bicycle (60; 1.68\%); Walking (48; $1.35 \%)$.

associated with higher odds of having good self-perceived health, higher vitality, and higher odds of having contact with friends and/or family at least once a week.

The models with dichotomous transport mode use (Supplementary material Table S3) and the meta-analyses showed similar results with only slight differences (Supplementary material from Fig. S3 to Fig. S14).

\section{Discussion}

\subsection{Summary of results}

Bicycle use was associated with good self-perceived health, lower perceived stress, better mental health, and higher vitality in the single and multiple transport mode models. Bicycle use was also associated with fewer feelings of loneliness in the multiple mode models. Walking was associated with higher vitality in the single and multiple mode models, and with good self-perceived health and having contact with friends/family only in the multiple mode models. We found that a higher frequency of car and public transport use was associated with poor self-perceived health in the single transport mode models. Car use was also associated with lower vitality in the single mode model, but also with fewer feelings of loneliness in the single and multiple mode models. The results of motorbike and e-bike use were inconclusive.

\subsection{Comparison with previous studies}

Bicycle use showed the most robust results throughout all the different analyses. Our results are in line with previous studies that associated bicycle use with better health outcomes: perceived general health (Scheepers et al., 2015), perceived stress (Avila-Palencia et al., 2017), mental well-being (Martin et al., 2014; Mytton et al., 2016), and quality of life (de Geus et al., 2008). Qualitative research has suggested that choice of travel mode may affect well-being due to the fact that travelling (mainly commuting) can be perceived as a relaxing or transitional time between home and work life, which can also be about enjoying pleasant landscape, nature, and wildlife (Guell and Ogilvie, 2015). Previous studies have found that cyclists perceived their work commute as relatively relaxing and exciting (Gatersleben and Uzzell, 2007; Lajeunesse and Rodríguez, 2012), have the highest commute well-being (Smith, 2017), and are the most satisfied travellers (Willis et al., 2013). Therefore, all the positive health effects we found could be a result of a repeated high travel satisfaction in daily life. It has been suggested that these levels of satisfaction could be explained because bicycling may offer independence, may be economical and pleasant, may create identity (cyclists may self-identify as "cyclists"), and generally those who use bicycle may cover shorter distances, so they may tend to have shorter commutes (Willis et al., 2013). Another thing to highlight is that to our knowledge, our study is the first to assess the association of bicycle use with social contact measures. We found a statistically significant association with fewer feelings of loneliness in the multiple mode models in the main models and in the meta-analyses. Our results suggest that analysis with multiple transport modes is maybe needed to be able to identify the bicycle use effects on social contact measures. It has been suggested that transport mode use can affect social perceptions and therefore it can have significant implications for community well-being and cohesion. Gatersleben et al. 2013 did a study to explore whether the mode by which people travel through a neighbourhood affects the views they form of the environment and the social situation. They made participants watch a video showing a journey in which the participant saw a view of young people from a walking, cycling, sitting on a bus or sitting in a car perspective. The results found that cyclists felt less annoyance about what they were seeing and reported significantly more positive views of the young people in the street than car drivers. These results suggest that the use of bicycle as a transport mode could help to improve social cohesion in a community/neighbourhood, ergo reduce feelings of loneliness of its population.

Walking was associated with positive health effects mainly in the multiple transport mode models. Previous literature on walking and similar health metrics has been inconclusive. On one hand, walking as a mode of transport has been associated with psychological well-being (Martin et al., 2014) and with more satisfying and happier trips than driving a car (Smith, 2017; St-Louis et al., 2014). Specifically, it has been suggested that walkers perceive their work commute as relatively relaxing and exciting (Gatersleben and Uzzell, 2007), have more time affluence (time to engage activities that are meaningful and growthpromoting), higher mindfulness, and lower degrees of commute dissonance (ratio between actual and ideal commute times) than drivers (Lajeunesse and Rodríguez, 2012). Perceptions as having low commute dissonance are also important in terms of health outcomes, as they could lead to a higher perceived control, which can result in lower stress levels. On the other hand, Richards et al. 2015 found small positive associations with happiness for walking, but no significant associations for the transport domain. Scheepers et al. 2015 found that, in comparison with car use, walking was neither associated with 
Table 2

Main characteristics of the population according to each questionnaire.

\begin{tabular}{|c|c|c|c|}
\hline & $\begin{array}{l}\text { Baseline } \\
\text { questionnaire } \\
(\mathrm{n}=8802)\end{array}$ & $\begin{array}{l}\text { Final questionnaire } \\
(\mathrm{n}=3567)\end{array}$ & p-Value ${ }^{a}$ \\
\hline & $\begin{array}{l}\text { Median (IQR) or } n \\
(\%)\end{array}$ & $\begin{array}{l}\text { Median (IQR) or } \mathrm{n} \\
(\%)\end{array}$ & \\
\hline Age & $38(20)$ & $41(20)$ & $<0.001$ \\
\hline Sex (Female) & $4675(53.1 \%)$ & $1872(52.5 \%)$ & 0.524 \\
\hline $\begin{array}{l}\text { University or higher } \\
\text { education }\end{array}$ & $6173(70.1 \%)$ & $2567(72 \%)$ & $<0.001$ \\
\hline Having nationality & $7612(86.5 \%)$ & $3042(85.3 \%)$ & $<0.001$ \\
\hline Full-time employed & $5270(59.9 \%)$ & $2290(64.2 \%)$ & $<0.001$ \\
\hline $\begin{array}{l}\text { Self-perceived health } \\
\text { (good or more) }\end{array}$ & $7493(85.1 \%)$ & $3130(87.7 \%)$ & $<0.001$ \\
\hline $\begin{array}{l}\text { Perceived stress (scale } \\
\quad 0-16)\end{array}$ & & $4(4)$ & \\
\hline $\begin{array}{l}\text { Mental Health (scale } \\
0-100 \text { ) }\end{array}$ & & $76(20)$ & \\
\hline Vitality (scale $0-100$ ) & & $65(20)$ & \\
\hline Loneliness (scale 6-30) & & $10(5)$ & \\
\hline $\begin{array}{l}\text { Contact with friends/ } \\
\text { family (at least once } \\
\text { a week) }\end{array}$ & & $3290(92.2 \%)$ & \\
\hline $\begin{array}{l}\text { Physical activity } \\
\text { behaviours (MET- } \\
\text { minutes/week) }\end{array}$ & & & \\
\hline Working & $0(240)$ & $0(300)$ & 0.706 \\
\hline Recreational & $960(1800)$ & $960(1560)$ & 0.601 \\
\hline Transport & $1120(1560)$ & $1185(1540)$ & 0.214 \\
\hline $\begin{array}{l}\text { Overall Physical } \\
\text { Activity }\end{array}$ & 2808 (3267) & $2781(3200)$ & 0.958 \\
\hline Sitting (minutes/day) & $480(270)$ & $480(240)$ & $<0.001$ \\
\hline $\begin{array}{l}\text { Body Mass Index (kg/ } \\
\mathrm{m}^{2} \text { ) }\end{array}$ & $23.31(4.56)$ & $23.34(4.61)$ & 0.179 \\
\hline \multicolumn{4}{|l|}{$\begin{array}{l}\text { Transport mode (days/ } \\
\text { month) [mean (SD)] }\end{array}$} \\
\hline Car & $6.62(7.85)$ & $6.67(7.54)$ & 0.002 \\
\hline Motorbike & $1.26(4.83)$ & 1.04 (4.29) & 0.116 \\
\hline Public transport & $11.77(10.21)$ & $11.25(9.93)$ & 0.067 \\
\hline E-bike & $0.59(3.39)$ & $0.96(4.24)$ & $<0.001$ \\
\hline Bicycle & $10.84(10.70)$ & $10.34(10.60)$ & 0.006 \\
\hline Walking & $19.26(8.27)$ & $17.88(8.68)$ & $<0.001$ \\
\hline \multicolumn{4}{|l|}{ Changing life events } \\
\hline Moved home & & $712(20 \%)$ & \\
\hline Started a new job & & $679(19 \%)$ & \\
\hline Follow-up days & & $522(372)$ & \\
\hline City & & & $<0.001$ \\
\hline Antwerp & $1294(14.7 \%)$ & $570(16 \%)$ & \\
\hline Barcelona & $1399(15.9 \%)$ & $572(16 \%)$ & \\
\hline London & $1089(12.4 \%)$ & $504(14.1 \%)$ & \\
\hline Oerebro & $1067(12.1 \%)$ & $351(9.8 \%)$ & \\
\hline Rome & $1585(18 \%)$ & $514(14.4 \%)$ & \\
\hline Vienna & $1204(13.7 \%)$ & $577(16.2 \%)$ & \\
\hline Zurich & $1164(13.2 \%)$ & $479(13.4 \%)$ & \\
\hline
\end{tabular}

a U Mann Whitney test for continuous variables and Chi square test for categorical variables. Missing data in the Baseline Questionnaire: University or Higher education (293; 3.33\%); Having nationality (238; 2.7\%); Full-time employed (224; 2.54\%); Self-perceived health (good or more) (170; 1.93\%); Working Physical Activity (910; 10.34\%); Recreational Physical Activity (910; 10.34\%); Transport Physical Activity (910; 10.34\%); Overall Physical Activity (910; 10.34\%); Sitting (minutes/day) (1061; 12.05\%); Body Mass Index (kg/ $\mathrm{m}^{2}$ ) (249; 2.83\%); Car (51; 0.58\%); Motorbike (65; 0.74\%); Public transport (33; 0.37\%); E-bike (65; 0.74\%); Bicycle (70; 0.8\%); Walking (50; 0.57\%). Missing data in the Final Questionnaire: University or Higher education (188; 5.27\%); Having nationality (174; 4.88\%); Full-time employed (95; 2.66\%); Selfperceived health (good or more) (83; 2.33\%); Perceived stress (scale 0-16) (91; 2.55\%); Vitality (scale 0-100) (87; 2.44\%); Mental Health (scale 0-100) (87; $2.44 \%)$; Loneliness (scale $6-30)(81 ; 2.27 \%)$; Contact with friends/family (at least once a week) (81; 2.27\%); Working Physical Activity (429; 12.03\%); Recreational Physical Activity (429; 12.03\%); Transport Physical Activity (429; 12.03\%); Overall Physical Activity (429; 12.03\%); Sitting (minutes/day) (495; $13.88 \%)$; Body Mass Index $\left(\mathrm{kg} / \mathrm{m}^{2}\right)(93 ; 2.61 \%)$; Car $(49 ; 1.37 \%)$; Motorbike (85; 2.38\%); Public transport (44; 1.23\%); E-bike (88; 2.47\%); Bicycle (60;
1.68\%); Walking (48; 1.35\%); Started a new job (12; 0.34\%).

perceived general health nor with psychological well-being. Also Mytton et al. 2016 did not find statistically significant associations between walking and mental well-being. Regarding to social contact measures, our results, as the bicycle use ones, are in line with Gatersleben et al. 2013 results, where walkers reported significantly more positive views and felt less threatened of the young people in the street than car users. All the detailed studies assessed walking as a single transport mode or compared it with other modes. Taking into account our results and the inconsistency of the literature, it seems that a more comprehensive analysis including multiple transport modes is needed to be able to distinguish the effects of walking on health and social contact measures from the other modes of transport.

Car use was associated with fewer feelings of loneliness in the single and multiple mode models. To our knowledge, there are very few studies evaluating association between transport and social contact measures. Our results do not support findings from a previous study which concluded that car commuting was significantly associated with low social participation and low general trust (Mattisson et al., 2015). Two important differences between our study and Mattisson's which could explain the discrepancy are: (1) our study evaluated transport modes independently of the purpose, while Mattisson et al. 2015 focused on commuting to work; and (2) Mattisson et al. 2015 evaluated commuting for residents across a wide geographical region, whereas we recruited participants within cities. This could also explain that in our study population car driving was not so frequent and the median distance from home to work/study was around $5 \mathrm{~km}$ (Supplementary material Table S4). All this information suggests that perhaps most of the car trips undertaken by our study population were socially-oriented trips not car commuting trips, which could explain the positive association with loneliness feelings.

The use of car and public transport were the only transport modes that showed negative effects. The negative effects of car use are in line with previous research that suggested car driving as the most stressful mode of transport (Novaco and Gonzalez, 2009; Legrain et al., 2015; Mattisson et al., 2016). However, the negative effects found were neither statistically significant in the multiple mode models, nor in the dichotomous sensitivity analyses. These results may suggest a spurious association between car use and self-perceived health and vitality in the single mode models, likely due to residual confounding from not taking into account all the transport modes. Public transport was statistically significant associated with poor self-perceived health in the single mode models and in all dichotomous sensitivity analyses. This association was not statistically significant in the multiple mode models. The negative health effects of public transport are not so clear either. Public transport results are in line with previous research that suggested an association of public transport with unsatisfying trips due to several factors like inappropriate treatment by employees, lack of punctuality, or discomfort with the use of vehicles and space (Eriksson et al., 2013). Therefore it could be argued that public transport's negative health effects stem from people's cognitive evaluations of their life circumstances, being in this case the low travel satisfaction.

The health effects of motorbike use were unclear and no statistically significant results were found for e-bike. Motorbike and e-bike were the least represented transport modes in our study population leading to low statistical power and inconclusive results.

\subsection{Limitations and strengths}

Our study had some limitations. First, our study population was highly educated and younger than the general population (GauppBerghausen et al., n.d.). This may be a consequence of the mainly opportunistic recruitment strategy done in PASTA, leading to a study population with more interest in the topic and perhaps healthier lifestyles than the general population. Second, we used self-reported data 


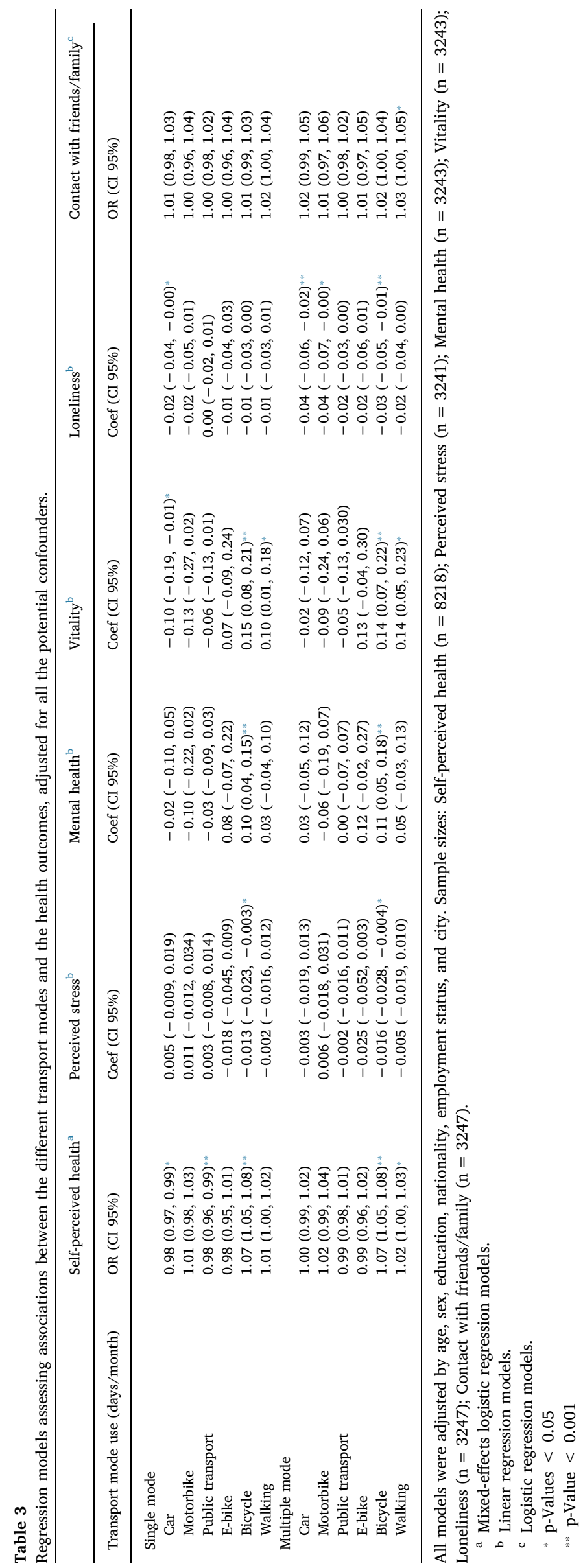


to assess use of transport modes, which may be imprecise and can be prone to recall bias. Third, our study population had a low representation of car, motorbike, and e-bike use, which could lead to an underestimation of the effects of car use, and ended in inconclusive results of the effects of motorbike and e-bike use. Finally, we cannot infer causality due to the limited number of repetitions in self-perceived health models and to the cross-sectional design for the rest of outcomes.

This study had several strengths too. First, to our knowledge, this was the largest study evaluating associations between the use of different transport modes and health and social contact measures. Second, we explored the associations using data from participants from different European cities with different travel behaviours. Therefore, we analyzed associations using both pooled analyses and stratified by city using the meta-analyses as sensitivity analyses. The pooled analyses results were fairly consistent with the meta-analyses results suggesting that we accounted properly for city effects, which may be due to cultural, social, and other differences between cities. Third, bicycle use was oversampled making possible to analyze this transport mode separately from walking. Fourth, we used validated questionnaires to measure all our outcomes (with the exception of contact with friends/ family). Although the measurement of the outcomes was self-reported, this is entirely appropriate for our outcomes. Also, it is well documented that our main outcome (self-perceived health) provides a good summary of health status (Ware et al., 1993). This outcome was measured in both questionnaires and had the biggest sample size of all our measurements, providing fairly robust results. Finally, we conducted single and multiple mode analyses. Multiple mode models may be more realistic as they account for multiple mode use which is a reality for many people nowadays and isolates the effect of specific modes after adjustment for others.

\subsection{Conclusions}

Evidence from this study provides robust results for the observation that bicycling is associated with several positive health effects. Also highlight our results for walking, as positive health effects came up after adjusting for all transport modes. An integrated management of urban design, transport planning, and public health is needed to develop policies to promote active transport and trying to integrate in people's mind that transport is not only about moving is also about public health and population's well-being.

\section{Acknowledgements}

ISGlobal is a member of the CERCA Programme, Generalitat de Catalunya. The authors are grateful to the participants of Physical Activity through Sustainable Transportation Approaches (PASTA) project. We would like to acknowledge David Martínez and Esther Gracia for their help with the statistical analyses.

\section{Funding}

This work was supported by the European project PASTA, which had partners in London, Rome, Antwerp, Örebro, Vienna, Zurich, and Barcelona. PASTA (http://www.pastaproject.eu/) was a 4-year project funded by the European Union's Seventh Framework Program under EC-GA No. 602624-2 (FP7-HEALTH-2013-INNOVATION-1). ED was supported by a postdoctoral scholarship from FWO - Research Foundation Flanders. JPO was financed by the Colombian Government, Colciencias Scholarship for PhD's abroad number 646. The funding sources had no involvement in the study. MJN had full access to all the data in the study and had final responsibility for the decision to submit for publication.

\section{Contributors}

$\mathrm{CB}$, AdN, TG, LIP, and MJN wrote the original grant proposal on which the study design and paper is based. ER and RG helped coordinate the overall work in PASTA. TG, RG, AdN, LIP, and ED led the development of the conceptual framework and survey design for the longitudinal study. IAP and MJN led the final questionnaire design. EAB, JPO, IAP, ES, FI, RG, ER, MGB, TG, and ED contributed with the participant recruitment process and data collection in the different cities. CB and TG coordinated the analysis and publication process of PASTA. IAP conducted the analyses and drafted this version of the paper and received input from all the authors. All the authors read and commented on the paper and agreed with the final version.

\section{Declaration of interests}

None.

\section{Appendix A. Supplementary data}

Supplementary data to this article can be found online at https:// doi.org/10.1016/j.envint.2018.08.002.

\section{References}

Avila-Palencia, I., de Nazelle, A., Cole-Hunter, T., et al., 2017. The relationship between bicycle commuting and perceived stress: a cross-sectional study. BMJ Open 7 (6), e013542. https://doi.org/10.1136/bmjopen-2016-013542.

Bakrania, K., Edwardson, C.L., Khunti, K., Bandelow, S., Davies, M.J., Yates, T., 2017. Associations between sedentary behaviours and cognitive function: cross-sectional and prospective findings from the UK Biobank. Am. J. Epidemiol. 187 (3), 441-454. https://doi.org/10.1093/aje/kwx273.

Besser, L.M., Marcus, M., Frumkin, H., 2008. Commute Time and Social Capital in the U.S. Am. J. Prev. Med. 34 (3), 207-211. https://doi.org/10.1016/j.amepre.2007.12.004.

Brand, C., Goodman, A., Rutter, H., Song, Y., Ogilvie, D., 2013. Associations of individual, household and environmental characteristics with carbon dioxide emissions from motorised passenger travel. Appl. Energy 104, 158-169. https://doi.org/10.1016/J. APENERGY.2012.11.001.

Brown, B.B., Werner, C.M., Tribby, C.P., Miller, H.J., Smith, K.R., 2015. Transit use, physical activity, and body mass index changes: objective measures associated with complete street light-rail construction. Am. J. Public Health 105 (7), 1468-1474. https://doi.org/10.2105/AJPH.2015.302561.

Celis-Morales, C.A., Lyall, D.M., Welsh, P., et al., 2017. Association between active commuting and incident cardiovascular disease, cancer, and mortality: prospective cohort study. BMJ 357357, j1456. https://doi.org/10.1136/bmj.j1456.

Cohen, S., Kamarck, T., Mermelstein, R., 1983. A global measure of perceived stress. J. Health Soc. Behav. 24 (4), 385-396.

Dadvand, P., Bartoll, X., Basagaña, X., et al., 2016. Green spaces and General Health: Roles of mental health status, social support, and physical activity. Environ. Int. 91, 161-167. https://doi.org/10.1016/j.envint.2016.02.029.

Dons, E., Temmerman, P., Van Poppel, M., Bellemans, T., Wets, G., Int, Panis L., 2013. Street characteristics and traffic factors determining road users' exposure to black carbon. Sci. Total Environ. 447, 72-79. https://doi.org/10.1016/j.scitotenv.2012.12. 076.

Eriksson, L., Friman, M., Gärling, T., 2013. Perceived attributes of bus and car mediating satisfaction with the work commute. Transp. Res. A Policy Pract. 47, 87-96. https:// doi.org/10.1016/J.TRA.2012.10.028.

Gatersleben, B., Uzzell, D., 2007. Affective Appraisals of the Daily Commute Comparing Perceptions of Drivers, Cyclists, Walkers, and Users of Public Transport. Environ Behav. 39, 416-431. https://doi.org/10.1177/0013916506294032.

Gatersleben, B., Murtagh, N., White, E., 2013. Hoody, goody or buddy? How travel mode affects social perceptions in urban neighbourhoods. Transport. Res. F: Traffic Psychol. Behav. 21, 219-230. https://doi.org/10.1016/J.TRF.2013.09.005.

Gaupp-Berghausen M, Raser E, Anaya E, et al. Evaluating Different Recruitment Methods in a Longitudinal Survey: Findings from the Pan-European PASTA Project. Preprint. https://doi.org/10.2196/preprints.11492.

Gerike, R., de Nazelle, A., Nieuwenhuijsen, M., et al., 2016. Physical Activity through Sustainable Transport Approaches (PASTA): a study protocol for a multicentre project. BMJ Open 6 (1), e009924. https://doi.org/10.1136/bmjopen-2015-009924.

de Geus, B., Van Hoof, E., Aerts, I., Meeusen, R., 2008. Cycling to work: influence on indexes of health in untrained men and women in Flanders. Coronary heart disease and quality of life. Scand. J. Med. Sci. Sports 18 (4), 498-510. https://doi.org/10. 1111/j.1600-0838.2007.00729.x.

de Gierveld, J.J., van Tilburg, T., Dykstra, P., 2016. Loneliness and social isolation. In: The Cambridge Handbook of Personal Relationships, . https://repub.eur.nl/pub/ 93235/ (Accessed October 26, 2017).

Giles-Corti, B., Vernez-Moudon, A., Reis, R., et al., 2016. City planning and population health: a global challenge. Lancet 388 (10062), 2912-2924. https://doi.org/10. 
1016/S0140-6736(16)30066-6

Guell, C., Ogilvie, D., 2015. Picturing commuting: photovoice and seeking well-being in everyday travel. Qual. Res. 15 (2), 201-218. https://doi.org/10.1177/ 1468794112468472.

Hamer, M., Chida, Y., 2008. Active commuting and cardiovascular risk: a meta-analytic review. Prev. Med. 46 (1), 9-13. https://doi.org/10.1016/j.ypmed.2007.03.006.

Humphreys, D.K., Goodman, A., Ogilvie, D., 2013. Associations between active commuting and physical and mental wellbeing. Prev. Med. 57 (2), 135-139. https://doi. org/10.1016/j.ypmed.2013.04.008.

Kelly, P., Kahlmeier, S., Götschi, T., et al., 2014. Systematic review and meta-analysis of reduction in all-cause mortality from walking and cycling and shape of dose response relationship. Int. J. Behav. Nutr. Phys. Act. 11, 132. https://doi.org/10.1186/ s12966-014-0132-x.

Lajeunesse, S., Rodríguez, D., 2012. a. Mindfulness, time affluence, and journey-based affect: exploring relationships. Transport. Res. F: Traffic Psychol. Behav. 15 (2), 196-205. https://doi.org/10.1016/j.trf.2011.12.010.

Legrain, A., Eluru, N., El-Geneidy, A.M., 2015. Am stressed, must travel: the relationship between mode choice and commuting stress. Transport. Res. F: Traffic Psychol. Behav. 34, 141-151. https://doi.org/10.1016/J.TRF.2015.08.001.

Martin, A., Goryakin, Y., Suhrcke, M., 2014. Does active commuting improve psychological wellbeing? Longitudinal evidence from eighteen waves of the British Household Panel Survey. Prev. Med. 69, 296-303. https://doi.org/10.1016/j.ypmed.2014.08. 023.

Mattisson, K., Hakansson, C., Jakobsson, K., 2015. Relationships between commuting and social capital among men and women in Southern Sweden. Environ. Behav. 47 (7), 734-753. https://doi.org/10.1177/0013916514529969.

Mattisson, K., Jakobsson, K., Håkansson, C., et al., 2016. Spatial heterogeneity in repeated measures of perceived stress among car commuters in Scania, Sweden. Int. J. Health Geogr. 15 (1), 22. https://doi.org/10.1186/s12942-016-0054-8.

Mytton, O.T., Panter, J., Ogilvie, D., 2016. Longitudinal associations of active commuting with wellbeing and sickness absence. Prev. Med. 84, 19-26. https://doi.org/10. 1016/J.YPMED.2015.12.010.

de Nazelle, A., Nieuwenhuijsen, M.J., Antó, J.M., et al., 2011. Improving health through policies that promote active travel: a review of evidence to support integrated health impact assessment. Environ. Int. 37 (4), 766-777. https://doi.org/10.1016/j.envint. 2011.02.003.

Nieuwenhuijsen, M.J., Khreis, H., 2016. Car free cities: Pathway to healthy urban living. Environ. Int. 94, 251-262. https://doi.org/10.1016/j.envint.2016.05.032.

Nieuwenhuijsen, M.J., Khreis, H., Verlinghieri, E., Rojas-Rueda, D., 2016. Transport and health: a marriage of convenience or an absolute necessity. Environ. Int. 88, 150-152. https://doi.org/10.1016/j.envint.2015.12.030.

Novaco, R.W., Gonzalez, O.I., 2009. Commuting and well-being. In: Amichai-Hamburger, Yair (Ed.), Technology and Psychological Well-Being. Cambridge University Press. https://doi.org/10.1017/CBO9780511635373.008.
Oja, P., Titze, S., Bauman, A., et al., 2011. Health benefits of cycling: a systematic review. Scand. J. Med. Sci. Sports 21 (4), 496-509. https://doi.org/10.1111/j.1600-0838. 2011.01299.x.

Richards, J., Jiang, X., Kelly, P., Chau, J., Bauman, A., Ding, D., 2015. Don't worry, be happy: cross-sectional associations between physical activity and happiness in 15 European countries. BMC Public Health 15. https://doi.org/10.1186/s12889-0151391-4.

Rissel, C., Curac, N., Greenaway, M., Bauman, A., 2012. Physical activity associated with public transport use-a review and modelling of potential benefits. Int. J. Environ. Res. Public Health 9 (12), 2454-2478. https://doi.org/10.3390/ijerph9072454.

Rodrigues, E.M.S., Villaveces, A., Sanhueza, A., Escamilla-Cejudo, J.A., 2014. Trends in fatal motorcycle injuries in the Americas. Int. J. Inj. Control Saf. Promot. 21 (2), 170-180. https://doi.org/10.1080/17457300.2013.792289.

Russel, D.W., 1996. UCLA Loneliness Scale (Version 3): Reliability, Validity, and Factor Structure. J Pers Assess 66 (1), 20-40. https://doi.org/10.1207/ s15327752jpa6601_2.

Saunders, L.E., Green, J.M., Petticrew, M.P., et al., 2013. What are the health benefits of active travel? A systematic review of trials and cohort studies. Ruiz JR, ed. PLoS One 8 (8), e69912. https://doi.org/10.1371/journal.pone.0069912.

Scheepers, C.E.E., Wendel-Vos, G.C.W.C.W., van Wesemael, P.J.V.J.V., et al., 2015 Perceived health status associated with transport choice for short distance trips. Prev Med Reports. 2 (February 2016), 839-844. https://doi.org/10.1016/j.pmedr.2015. 09.013.

Sener, I.N., Lee, R.J., Elgart, Z., 2016. Potential health implications and health cost reductions of transit-induced physical activity. J Transp Heal. 3 (2), 133-140. https:// doi.org/10.1016/J.JTH.2016.02.002.

Smith, O., 2017. Commute well-being differences by mode: evidence from Portland, Oregon, USA. J Transp Heal. 4, 246-254. https://doi.org/10.1016/j.jth.2016.08.005.

St-Louis, E., Manaugh, K., van Lierop, D., El-Geneidy, A., 2014. The happy commuter: a comparison of commuter satisfaction across modes. Transport. Res. F: Traffic Psychol. Behav. 26, 160-170. https://doi.org/10.1016/j.trf.2014.07.004.

Wanner, M., Götschi, T., Martin-Diener, E., Kahlmeier, S., Martin, B.W., 2012. Active transport, physical activity, and body weight in adults: a systematic review. Am. J. Prev. Med. 42 (5), 493-502. https://doi.org/10.1016/j.amepre.2012.01.030.

Ware, J.E., Snow, K.K., Kosinski, M., Gandek, B., 1993. SF-36 health survey manual and interpretation guide. In: Bost New Engl Med Cent. vol. 1 (various pagings). http:// books.google.com/books/about/SF 36 health survey.html?id = WJsgAAAAMAAJ.

Willis, D.P., Manaugh, K., El-Geneidy, A., 2013. Uniquely satisfied: exploring cyclist satisfaction. Transp. Res. F Psychol. Behav. 18, 136-147. https://doi.org/10.1016/j.trf. 2012.12.004.

Xu, H., Wen, L.M., Rissel, C., 2013. The relationships between active transport to work or school and cardiovascular health or body weight: a systematic review. Asia Pac. J. Public Health 25 (4), 298-315. https://doi.org/10.1177/1010539513482965. 